\section{PARADOXO DA IGUALDADE: GÊNERO, RAÇA E DEMOGRAGIA}

\author{
Flavia Rios \\ Ana Claudia Pereira \\ Patrícia Rangel
}

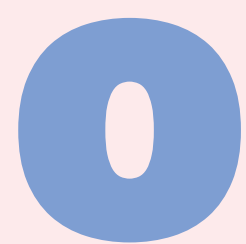

nze de maio de 2016. O Senado é o foco de todos os olhares. Nessa data e nesse local, decidia-se pelo afastamento da primeira e única mulher a ocupar a Presidência da República, uma das principais páginas do tortuoso processo de impeachment de Dilma Rousseff. Na casa legislativa, a senadora Regina Sousa (PT/ PI), negra, fazia seu pronunciamento contrário à admissibilidade do impedimento da presidenta. Em resposta imediata, um humorista brasileiro lança uma mensagem no Twitter: "Senadora? Achei que fosse a tia do café...” (1). O escárnio em forma de pergunta, embora tivesse o nítido objetivo de provocar risos dos seus seguidores na internet, gerou reações expressivas (de concordância e desagravo), repercutindo, assim, nas redes sociais e, na sequência, em alguns noticiários. A suposta confusão do comediante, longe de ser uma opinião particular, revela-se, antes, um tipo de retórica padrão com base em estereótipos racistas, sexistas e de classe, presentes em discursos hegemônicos acionados mediante o estranhamento da presença de pessoas de certos grupos sociais em posições de poder econômico, de status social ou prestígio político, as quais julgam estar "fora do lugar".

Pelo menos desde o processo de retomada democrática, ativistas e intelectuais feministas e antirracistas têm destacado a importância da representação social (2) para a compreensão das desigualdades de gênero e raça nas diversas esferas da vida em sociedade (3). No que compete à desigualdade na política institucional, esforços acadêmicos têm sido feito no sentido de descrever, mensurar e explicar a baixa representação de mulheres e negros nos espaços de poder político, em especial nas esferas parlamentares. O diagnóstico comum da literatura acadêmica versada na temática da representação política tem apontado que as instituições de poder que conformam a democracia brasileira possuem ocupantes pertencentes a grupos sociais bastante específicos. A predominância de homens brancos em proporçôes muito superiores às apresentadas na população brasileira faz supor que existem mecanismos seletivos que têm favorecido tais segmentos sociais em detrimento de outros, reproduzindo uma hierarquia racial e de gênero, da base ao topo da política representativa nacional.

No veio deste debate, o presente artigo tem por objetivo contribuir com esse campo de investigação, ampliando o foco analítico da produção acadêmica ao assinalar a pertinência da perspectiva interseccional - e não apenas a análise isolada dos atributos de gênero ou raça - para os estudos das desigualdades persistentes e categóricas na representação política (4). Advoga-se aqui que a abordagem interseccional é sensível aos pontos nodais de desigualdades, uma vez que observa tanto "as diferenças entre as mulheres como as diferenças entre mulheres e homens", conforme formula Crenshaw (5). Esse mesmo raciocínio vale também para as desigualdades raciais intra e entre grupos, uma vez que o foco analítico está nos imbricamentos geradores e reprodutores de desigualdades, especialmente aqueles que articulam gênero, raça e classe (6).

Esse tipo de argumentação teve lugar no seio da intelectualidade negra brasileira entre os anos de 1970 e 1980 . Lélia Gonzalez (7), influenciada pelos estudos das relações raciais brasileiras, pelos nascentes estudos nacionais sobre as hierarquias de gênero e pelo marxismo estruturalista, bem como pelo pensamento do Black $\mathrm{Fe}$ minism, chamou a atenção para as desigualdades geradas pelas opressões racial e sexista, bem como pela exploração de classe (7; 8). Com efeito, os estudos sobre desigualdades no mercado de trabalho e nos rendimentos demostraram as fortes e persistentes assimetrias salariais e de inserção ocupacional quando se considera a intersecção entre raça e gênero, reservando maiores vantagens para os homens brancos e maior acúmulo de desvantagens para as mulheres negras (9).

Deslocando essa problemática da vida econômica e social para o âmbito da política institucional, neste artigo, serão abordados os seguintes aspectos: 1) a caracterização do perfil das candidaturas e dos eleitos à 55a legislatura da Câmara dos Deputados (2015-2019), por gênero e raça, considerando o desenvolvimento da produção acadêmica versada nas relações raciais e de gênero, com especial destaque para a representação política, dialogando, assim, com as contribuições das atuais tendências interpretativas que entrelaçam esses temas; e 2) a discussão acerca dos desafios e das perspectivas para uma agenda de pesquisa voltada para o tema da representação de negros e de mulheres na política brasileira, uma vez que se nota um paradoxo expresso na vigorosa participação política nas esferas civis e extraparlamentares, em contraste com a sua baixa representação nas estruturas representativas do estado democrático de direito.

REPRESENTAÇÃO PARLAMENTAR DAS MULHERES NEGRAS NA CÂMARA DOS DEPUTADOS, 55a LEGISLATURA (2015-2019) Por muito tempo, os estudos sobre desigualdades de raça e gênero andaram apartados. Apesar de trabalharem com a temática das desigualdades na política considerando características adstritas, as pesquisas sobre as relações raciais nesse campo não dialogavam com as pesquisas sobre gênero e vice-versa. Dentre as diversas razões que explicam tal realidade, uma delas pode ser atribuída à ausência de informações sobre cor nos documentos e estatísticas oficiais produzidas pelo Tribunal Superior Eleitoral (TSE). A emergente bibliografia sobre a sub-representação feminina contrasta com a escassez de estudos sobre a marginalidade da população negra nas instituições de política formal no Brasil. Como assinalaram Luiz Campos e Carlos Machado (10), pouco se 
sabe sobre os mecanismos sociais e institucionais que favorecem o predomínio de brancos nos quadros eleitos e até mesmo sobre a fase da carreira política em que os negros são afastados da representação.

Visando contribuir para o debate público acerca da relação entre desigualdades e democracia, esta seção se propõe a descrever a representação parlamentar das mulheres negras em contraste com outros grupos de raça e gênero na atual legislatura da Câmara dos Deputados. Seguindo as tendências das pesquisas acadêmicas versadas no tema das desigualdades, tomaremos aqui a categoria negro como sendo o somatório dos que se autodeclaram pretos e pardos nas fichas de inscrição do TSE. Nas eleiçōes de 2014, ano em que a informação sobre raça/cor foi incluída pela primeira vez nas fichas de candidatura, o número de negros eleitos para o Congresso Nacional chegou a 108. Dos 540 parlamentares ( 513 deputados e 27 senadores), 432 eram brancos (22 senadores e 410 deputados), sendo 45 mulheres e 387 homens. Entre os parlamentares negros, havia 11 mulheres e 97 homens (11), como se pode observar na tabela 1.

Tais dados evidenciam um contraste entre eleitos e a população brasileira. Dentre os parlamentares escolhidos para integrar o Congresso Nacional em 2014, somente 2\% correspondem a mulheres negras - um número ínfimo, considerando que as negras representam 25\% da população brasileira. Segundo o Censo de 2010 realizado pelo IBGE, 50,7\% dos brasileiros consideram-se negros, em contraste com $20 \%$ de deputados e $18,5 \%$ de senadores autodeclarados negros eleitos para a $55^{\text {a }}$ legislatura.

Afunilando a análise para a casa baixa do Congresso, dentre os 513 deputados da mencionada legislatura, apontamos que os brancos são 79,9\% (410 pessoas) e os negros são 20\%: os pardos são $15,8 \%$ (81) e os/as pretos/as são 4,3\% (22). Não foram eleitos deputados autodeclarados amarelos ou indígenas. Quanto às diferenças intra-grupos, vale destacar a distância entre as mulheres. Das 51 eleitas, $80,4 \%$ são brancas, e $19,6 \%$ são negras (13,7\% são pardas e $5,9 \%$ são pretas). Dos 462 deputados (homens) eleitos, 79,9\% são brancos e $20,1 \%$ são negros ( $16 \%$ são pardos e $4,1 \%$ são pretos).

Os eleitos brancos são mais numerosos do que os candidatos à Câmara dos Deputados: no momento das candidaturas, os autodeclarados brancos eram $58,1 \%$, os pardos eram $31,2 \%$, os pretos eram $9,8 \%$, os amarelos $0,5 \%$ e os indígenas eram $0,3 \%$. Dentre os eleitos, os brancos são $79,9 \%$, os pardos são $15,8 \%$ e os pretos são $4,3 \%$.

Tabela 1 - Resultados das eleições de 2014: Eleitos para Senado e Câmara dos Deputados, por raça/cor e gênero

\begin{tabular}{lccccccccccc}
\hline & Pretos & Pardos & \multicolumn{3}{c}{ Brancos } & Indígenas & \multicolumn{3}{c}{ Amarelos } & Total \\
\hline & H & M & H & M & H & M & H & M & H & M & \\
\hline Senado & 0 & 0 & 4 & 1 & 18 & 4 & 0 & 0 & 0 & 0 & $\mathbf{2 7}$ \\
Câmara & 19 & 3 & 74 & 7 & 369 & 41 & 0 & 0 & 0 & 0 & $\mathbf{5 1 3}$ \\
$\begin{array}{l}\text { Congresso } \\
\text { Nacional }\end{array}$ & 3 & 3 & 78 & 8 & 387 & 45 & 0 & 0 & 0 & 3 & $\mathbf{5 4 0}$ \\
\hline
\end{tabular}

Tais resultados parecem confirmar a hipótese apresentada por Campos e Machado, segundo a qual a sub-representação não é causada exclusivamente pelo menor número de negros entre os candidatos. Apesar de termos contabilizado menos negros que brancos nas listas de candidaturas, acreditamos que a proporção das assimetrias nas candidaturas não é suficiente para explicar a profundidade da sub-representação de negras na Câmara, após concluído o pleito.

A pesquisa de Bueno e Dunning (12) também mostrou que a sub-representação de negros não é somente explicada pela desigualdade na apresentação de candidaturas. Esse estudo indicou que o gargalo na participação de negros em cargos eletivos não pode ser atribuído a obstáculos às candidaturas e que as candidaturas brancas apresentam taxas maiores de sucesso, como indicamos no gráfico 1 . Em grande medida, isso se deve às singularidades do sistema eleitoral do país. A adoção de listas abertas e a forte individualização das campanhas políticas contribuem para que as mulheres negras tenham dificuldades para entrar no jogo eleitoral com possibilidades reais de eleição. É importante lembrar, como ressalta Clara Araújo (13), que a porcentagem de mulheres eleitas não cresce proporcionalmente à porcentagem de candidatas.

Um estudo da Seppir (14) sobre a legislatura anterior (54a legislatura: 2011-2015) indicou que houve 1.178 candidaturas femininas sobre um total de 6.028 à Câmara dos Deputados em 2010, o que correspondia a 22,2\%. Dessas, 241 (3,9\%) eram negras. Não é possível, contudo, oferecer uma comparação fiável com as eleições passadas, no que tange aos dados que embasam a análise, pois eles não são oferecidos pela mesma fonte: como o critério raça/cor só foi incluído nas fichas de candidatura do TSE em 2014, os dados sobre os outros pleitos foram produzidos por pesquisadores independentes, que recorreram à heteroclassificação racial ou aos partidos e representantes políticos $(12 ; 14 ; 15)$. Para além das diversas dificuldades e limitações desse tipo de análise, não é possível relacionar da-

\section{Gráfico 1 - Eleições de 2014: Candidatos x eleitos para Câmara dos Deputados, por raça/cor}

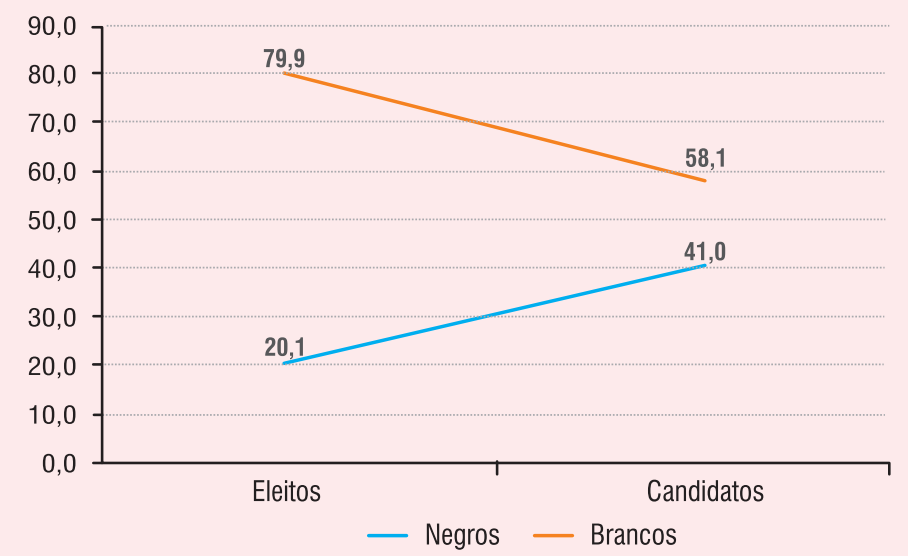

Fonte: Elaboração própria, com dados do TSE 
dos resultados de metodologias de heteroclassificação a informações oficiais (autoclassificação). Por maiores que tenham sido os esforços para definir com a maior precisão possível a cor/raça das candidatas, a metodologia possui desvios causados pela maneira subjetiva pela qual se realiza a classificação. Conforme apontou o pesquisador Luiz Augusto Campos, "é bem provável que uma parcela significativa dos deputados autodeclarados pardos e pretos não seja vista desse modo pela sociedade como um todo" (10). Esta é, ademais, uma questão já notada no estudo clássico sobre relaçōes raciais, de Oracy Nogueira, que assinala as flagrantes diferenças entre heteroclassificação e autoclassificação nas classificações identitárias de tipo fenotípica em oposição à de origem racial (16).

Em que pese essas ponderações, podemos nos valer desses dados para refletir sobre os resultados das eleições de 2014 em contraste com o pleito anterior. Um levantamento realizado pela União de Negros pela Igualdade (Unegro) com base na heteroclassificação (15) indicou que, em 2010, dos 567 parlamentares eleitos para a $54^{\mathrm{a}}$ legislatura do Congresso Nacional (2011-2015), incluindo Câmara e Senado, 522 eram pessoas brancas ( 46 mulheres e 476 homens) e 45 pessoas negras (6 mulheres e 39 homens) (17). Esse levantamento, portanto, indica que a representação parlamentar das mulheres negras mal conseguiu ultrapassar $1 \%$.

Focando na Câmara, ainda segundo o levantamento da Unegro (15), foram eleitos 43 deputados negros nas eleições de 2010. Embora a pesquisa não destaque a presença de mulheres negras, por meio dos nomes listados no relatório, é possível inferir que 7 são parlamentares pretas e pardas, ou seja, representavam $16 \%$ do conjunto dos negros eleitos para a casa legislativa federal na $54^{\mathrm{a}}$ legislatura. Três dessas mulheres elegeram-se pelo Partido dos Trabalhadores (Benedita da Silva, Janete Pietá e Dalva Figueiredo) e duas (Perpetua Almeida e Luciana Santos), pelo Partido Comunista do Brasil. As demais, Nice Lobão e Andreia Zito, foram eleitas pelo Partido Democratas (DEM) e pelo Partido da Social Democracia Brasileira (PSDB). Segundo o mesmo relatório, parte expressiva dos negros eleitos (18) representava a coligação PT-PCdoB, o que explicaria a maior concentração de mulheres negras eleitas nessas duas siglas partidárias. Em 2010, de acordo com dados do TSE, foram eleitas 45 deputadas federais. Se 7 delas eram negras, como indica o relatório da Unegro, as deputadas negras seriam 15,5\% das deputadas eleitas naquele ano, e o índice de representação das mulheres negras naquela legislatura teria sido de $1,4 \%$.

Quanto à legislatura anterior (53a legislatura: 2007-2011), uma pesquisa do CFEMEA (18) traçou o perfil da composição do Congresso, ilustrado por uma amostra de 321 (19) parlamentares que responderam ao questionário. Os homens foram $92 \%$ dos entrevistados e os brancos, $60 \%$. A pesquisa apontou que apenas $3 \%$ dos entrevistados se autodeclararam pretos e $30 \%$ pardos. O Relatório das Desigualdades Raciais 2007-2008 (20), por sua vez, investigou a quantidade de parlamentares negros da mesma legislatura a partir da heteroclassificação, e considerou que $87 \%$ dos deputados federais eram brancos, enquanto somente $9 \%$ foram identificados como negros. Entre os 513 eleitos, havia somente uma mulher preta e duas pardas. Como apontaram os pesquisadores, as mulheres negras correspondiam a aproximadamente $0,6 \%$ dos deputados eleitos, um número muito distante do peso das mulheres negras na população brasileira, que naquele ano era de $24,8 \%$.

Para buscar explicar os motivos da sub-representação, apoiamo-nos no amplo estudo de Bueno e Dunning (12) sobre candidatos para cargos majoritários dos níveis federal, estadual e municipal (presidência, governos dos estados, senado e prefeitura) e proporcionais (Câmara dos Deputados, Assembleias Legislativas e Câmaras dos Vereadores) de localidades selecionadas. Sua pesquisa indicou que a desigualdade na composição racial dos eleitores e dos eleitos ocorre em todos os níveis de governo, mas que as assimetrias favoráveis aos brancos são menores para cargos legislativos de âmbito municipal, aumentando no nível estadual e crescendo mais ainda no nível federal. Ademais, apontou que candidatos brancos são "substancialmente mais ricos", ostentando vantagens expressivas tanto no quesito patrimônio pessoal, quanto no volume de recursos recebidos para financiamento de campanha, incluindo recursos provenientes dos próprios partidos.

A pesquisa de Campos e Machado (10) indicou, ademais, acentuadas desigualdades entre candidatos brancos e não-brancos no acesso a financiamento de campanha. Entre candidatos negros, homens e com ensino superior, havia maior acesso a financiamento, mas, ainda assim, com desvantagem significativa em relação a candidatos brancos. Ao recortar a receita de campanha declarada pelos candidatos ao TSE, os autores descobrem que "é no conjunto dos estratos com maior chance de vitória eleitoral, onde há maior acirramento da competição, que opera um entrave quanto ao acesso a recursos importantes para candidatos não-brancos" (10). Mesmo quando somente candidatos com ensino superior são comparados, os negros encontram-se em desvantagem. Por fim, é importante destacar que um elemento que se repete nas duas pesquisas $(10 ; 12)$ foi a falta de evidências de que os candidatos não-brancos sejam discriminados pelos eleitores, sugerindo que os filtros raciais determinantes para o fracasso das candidaturas negras operam no interior dos sistemas partidário e eleitoral.

Esse breve olhar sobre números relativos à presença de mulheres, negros e mulheres negras entre os representantes políticos eleitos para a 55 $5^{\text {a }}$ legislatura permite dimensionar o acesso de indivíduos que compõem esses grupos sociais a assentos nas casas legislativas, identificando o racismo e o sexismo que estruturam as relaçôes sociais no país e que estabelecem o pano de fundo sobre o qual a parti- 
cipação política das negras ocorre. Esses dados relevam disparidades ainda mais acentuadas se considerarmos, como apontou a pesquisa de Bueno e Dunning (12), que a sobre-representação de brancos é maior em cargos executivos do que em cargos legislativos, conforme os dados coletados pela pesquisa da Seppir parecem corroborar na tabela 2. A Câmara dos Deputados, com 2\% de mulheres negras, não é o locus de maior sub-representação dessas mulheres.

É interessante notar, conforme indicaram os dados da Seppir sobre as eleiçōes gerais de 2010, que as mulheres negras estiveram mais presentes percentualmente na disputa ao cargo de vice-governadora $(27,6 \%)$, menos presentes na disputa ao Senado $(17,9 \%)$ e tiveram um peso relativamente homogêneo na corrida pelas Assembleias Legislativas (20,7\%) e pela Câmara Federal (20,5\%). Tal perfil indica que a posição simbólica de vice-governadora parece ser uma estratégia partidária para atrair certas parcelas do eleitorado, e indica também que as eleições executivas e majoritárias seguem sendo um dos maiores gargalos para a sub-representação feminina e negra. Estudos futuros que venham a acompanhar, em perspectiva longitudinal e comparativa, os desdobramentos das desigualdades por cor e gênero terão o desafio de explicar as diferenças entre as carreiras políticas e suas relaçôes com as desigualdades raciais e de gênero na democracia brasileira.

\section{DILEMAS E HORIZONTES PARA A REPRESENTAÇÃO POLÍTICA O}

tema da qualidade da democracia esteve no centro das preocupações dos movimentos feministas, negros e de mulheres negras, pelo menos, desde o término da ditadura militar. Entretanto, os agenciamentos políticos empreendidos por esses atores e atrizes, já nos primórdios da redemocratização, não foram capazes de reverter as disparidades por gênero e raça presentes nos espaços políticos institucionais de poder. Ao longo das últimas décadas, tais movimentos lograram ampliar espaços de participação política (a exemplo dos conselhos setoriais, como o da saúde e da educação, ou mesmo os específicos, como o Conselho Nacional de Políticas da Igualdade Racial e o Conselho Nacional dos Direitos da Mulher), tornaram-se agentes influentes na formulação de leis e de políticas públicas de equidade racial e de gênero (como no caso das cotas para negros no ensino superior, a reserva de candidaturas para mulheres nas eleições proporcionais - leis 9.100/95, 9.504/97 e $12.034 / 09$, a lei contra a discriminação racial e as leis Maria da Penha e do Feminicídio, ou ainda leis de reconhecimento, como a 10.639/03 ou 11.645/08, dentre outras). Esses grupos chegaram até mesmo a constituir secretarias e ministérios no governo federal, como a Secretaria de Políticas de Promoção da Igualdade Racial e a Secretaria de Políticas para as Mulheres, durante os governos de Lula e Dilma. Contudo, aqueles agentes não foram capazes de abalar as estruturas de caráter racial e patriarcal que conformam a democracia representativa brasileira.

Com efeito, um dos paradoxos de nossa democracia é exatamente esse: por que mulheres e negros, agentes tão vigorosos
Tabela 2- Mulheres negras nas eleições 2010 - por cargo, Brasil

\begin{tabular}{lccc}
\hline Cargo & Total negras & Total candidatas* & \% negras / Total \\
\hline Governadora & 0 & 13 & $0,0 \%$ \\
Vice-governadora & 8 & 29 & $27,6 \%$ \\
Senadora & 5 & 28 & $17,9 \%$ \\
$1^{\text {a Suplente senadora }}$ & 7 & 40 & $17,5 \%$ \\
2a Suplente senadora & 10 & 49 & $20,4 \%$ \\
Deputada federal & 241 & 1.178 & $20,5 \%$ \\
Deputada estadual & 604 & 2.916 & $20,7 \%$ \\
\hline Total & $\mathbf{8 7 5}$ & $\mathbf{4 . 2 5 3}$ & $\mathbf{2 0 , 6 \%}$ \\
\hline
\end{tabular}

* Somatório das candidatas classificadas como negras, não-negras e sem foto Fonte: Seppir, 2013

na formação e manutenção de organizações e movimentos sociais, formas políticas relevantes para a conformação democrática no país, são tão poucos nos espaços de representação institucional? Não existe uma explicação única. As razões que levam à sub-representação das mulheres - brancas e negras - e dos homens negros têm sido objeto de pesquisas acadêmicas. Infelizmente, os estudos sobre representação racial são parcos quando comparados aos das mulheres, estes mais numerosos, extensos e longevos. Todavia, observou-se que, com a introdução do quesito raça/cor na coleta do TSE, houve maior estímulo para a produção acadêmica interessada em monitorar, descrever e analisar as desigualdades raciais no país articuladas a outros atributos geradores de desigualdades categóricas e duráveis, como o gênero. Para o futuro, mais do que um acompanhamento estatístico das desigualdades, é preciso abrir agendas de pesquisas interessadas nas trajetórias das minorias políticas, especialmente quando estas são maiorias demográficas e estão em situaçôes de flagrante desvantagem econômica e social em outras esferas da vida, o que se faz também refletir nos espaços de poder político. Da literatura acadêmica especializada, destacam-se algumas razôes importantes para entender os mecanismos e processos que resultam na sub-representação parlamentar desses grupos sociais, já que essas estão na confluência dos determinantes de gênero e de raça:

a) os obstáculos enfrentados dentro dos próprios partidos, que dificultam o lançamento de candidaturas femininas e negras. As agremiações partidárias investem menos recursos em candidaturas de mulheres e de negros, apesar das cotas eleitorais para o primeiro grupo no caso de eleições proporcionais.

b) o baixo capital econômico dos negros que se encontram em estratos sociais menos privilegiados, além das dificuldades referentes ao capital educacional que poderia favorecer ampliação das redes de relacionamentos, conhecimentos específicos e habilidades discursivas, dentre outros. 
c) no caso das mulheres negras e indígenas, ademais, acrescente-se o complexo de coerçôes sociais relativas ao imbricamento das condições de gênero, raça e classe, que envolvem desde a dupla jornada até os aspectos relativos à violência simbólica, como a educação normativa colonial e patriarcal, reprodutoras de estereótipos que afixam grupos a certos lugares sociais, reduzindo expectativas (das potenciais candidatas e dos agentes que fazem os filtros e seleçôes das candidaturas), excluindo ou reduzindo as chances daquelas de ocuparem espaços de poder com elevado grau de competitividade.

Em que pesem as críticas e dilemas relacionados ao tema da representação política de natureza descritiva/presença e substantiva/ideias (21), o peso das desigualdades sociais parecem retroalimentar as desigualdades na política, e vice-versa. Do ponto de vista normativo, a diversidade racial e de gênero no espaço institucional da política tem implicações importantes no que toca à quebra de estereótipos fundamentados em visões coloniais do poder, ou seja, expondo estereótipos identitários, como no caso descrito na introdução deste artigo sobre o choque de representação gerado pela presença da senadora piauiense. Outra implicação importante do pluralismo descritivo da representação é a de criar - e não necessariamente de garantir - condições para que assuntos relevantes em matéria dos direitos das mulheres e dos negros tenham visibilidade nas esferas públicas decisórias, especialmente porque se trata de grupos historicamente sub-representados no sistema político.

Questôes como essas, de natureza empírica e teórica, abrem caminhos para novos e promissores interesses de pesquisas, bem como subsidiam o debate público acerca das desigualdades em sistemas democráticos. Mais do que descrever as discrepâncias entre categorias interseccionadas ao longo do tempo, é preciso também avançar no debate acerca dos determinantes das desigualdades políticas resultantes da articulação de múltiplos eixos de opressão, além de avançar na reflexão sobre os mecanismos capazes de corrigir disparidades dessa natureza, permitindo assim maior equidade nas instâncias representativas de poder político.

Flavia Rios é professora adjunta e integra o Programa de Pós-Graduação em Sociologia da Faculdade de Ciências Sociais da Universidade Federal de Goiás (UFG). Doutorou-se na USP e foi visiting student researcher collaborator na Princeton University, com bolsa sanduiche da Fapesp (2013).Email: flaviamrios@yahoo.com.br

Ana Claudia Pereira é doutora em ciência politica (IESP/UERJ). Desenvolve pesquisa nos temas de gênero e raça e atua no Grupo de Estudos Mulheres Negras da Universidade de Brasilia (UnB).Email: anaclaudiapereira@gmail.com

Patrícia Rangel é doutora em ciência politica (UnB) com missão de estudos na UNGS (Argentina). Atualmente, é bolsista de pós-doutorado da Fapesp, realizando sua pesquisa no Departamento de Sociologia da Faculdade de Filosofia, Letras e Ciências Humanas da Universidade de São Paulo (USP), junto ao projeto "50 anos de feminismo: Brasil, Argentina e Chile”.Email: pdrangel@gmail.com

\section{NOTAS E REFERÊNCIAS}

1. "Danilo Gentili é criticado após chamar senadora Regina Sousa de 'tia do café" em Catraca Livre, 12/05/2016. Disponível em: <https:// catracalivre.com.br/geral/cidadania/indicacao/danilo-gentili-e-criticado-apos-chamar-senadora-regina-sousa-de-tia-do-cafe/> Acesso em: 28/09/ 2016.

2. A fixação de imagens - os estereótipos - como bem notou Bell Hooks em Black looks: race and representation (New York: Routledge, 1992)e Stuart Hall em Questions of cultural identity (London, Thousand Oaks, New Delhi: Sage,1996) tem relação com representação política, já que se trata da natureza ideológica do imaginário que determina posições e papéis para "minorias" raciais que se veem e são vistas pelos grupos dominantes.

3. Não foi por acaso que, nos anos 1980 , foram produzidos dois livros com títulos bastante sugestivos: O lugar de negro, de Lélia Gonzalez e Carlos Hasenbalg (1982 ) e O lugar da mulher (1982), de Paula Monteiro et al.

4. Tilly, C. Democracia. Petrópolis: Editora Vozes. 2013.

5. Crenshaw, K. A intersecionalidade da discriminação de raça e gênero. 2002, p. 173. Disponível em: 〈http://www.acaoeducativa.org.br/fdh/ wpcontent/uploads/2012/09/Kimberle-Crenshaw.pdf> Acesso em: 13/11/2016. Sobre o conceito de interseccionalidade ver a referência de Kimberlé Crenshaw. Uma crítica construtiva do conceito pode ser encontrada em Lykke, N. "Intersectional analysis: black box or useful critical feminist thinking technology". In: Lutz, H.; Herrera Vivar, T. M.; Supik, L. (ed.) Framing intersectionality: debates on a multi-faceted concept in gender studies. Farnham: Ashgate Publishing Limited. 2011.

6. O debate teórico sobre o assunto pode ser encontrado em Kergot, D. "Dinâmica e consubstancialidade das relações sociais". In: Novos Estudos Cebrap, 86. 2010, p. 93-103. Também em Hirata, H. "Gênero, classe e raça". In: Tempo Social, revista de sociologia da USP, v. 26, n. 1. 2014, p. 61-73. Ou em Biroli, F.; Miguel, L. F. (2015). "Gênero, raça e classe: opressões cruzadas e convergência na reprodução das desigualdades". Mediações, v. 20 n. 2, p. 27-55.

7. Gonzalez, L. "A mulher negra na sociedade brasileira". In: Luz, M. (org.) O lugar da mulher: estudos sobre a condição feminina na sociedade atual. Rio de Janeiro: Graal, 1982.

8. Rios, F. e Ratts, A. "A perspectiva interseccional de Lélia Gonzalez". In: Chalhoub, S.; Pinto, F. (org.). Pensadores negros-pensadoras negras do século XIX e XX.1a.ed.Belo Horizonte: Traço Fino Ltda, 2016, p. 387-402.

9. Sobre as desigualdades a interseccção das desigualdades de gênero e raça, consultar: Soares, S. S. D. "O perfil da discriminação no mercado de trabalho - homens negros, mulheres brancas e mulheres negras". Texto para discussão, n 769, Brasília: IPea, novembro 2000. Lima, M.; Rios, F. e França, D. "Articulando gênero e raça". Dossiê Mulheres Negras. Ipea: Brasília, 2013.

10. Campos, L.A.; Machado, C. "A cor dos eleitos". In: Revista Brasileira de Ciência Política, n016. Brasília, janeiro - abril de 2015, pp. 121-151. 
11. Merece destaque o fato de que não houve senadores/as de cor preta, indígena ou amarela.

12. Bueno, N.; Dunning T. "Race, resources, and representation: evidence from Brazilian politicians, social science research network". 2014. Disponível em 〈https://ssrn.com/abstract=2498662〉 Acesso em: 13/11/ 2016.

13. Araujo, C. "Mujeres y elecciones legislativas en Brasil: las cuotas y su (in) eficácia". In: Archenti, N. \& Tula, M.I. (eds.). Mujeres y política en América Latina: sistemas electorales y cuotas de género. Buenos Aires: Heliasta, 2008.

14. Seppir - Secretaria de Promoção da Igualdade Racial, Ministério da Justiça e Cidadania. "A participação das mulheres negras nos espaços de poder". Brasília. Relatório disponível online, 2013.

15. Unegro, Balanço eleitoral do voto étnico e negro. Belo Horizonte. Disponível em <http://congressoemfoco.uol.com.br/upload/congresso/ arquivo/balanco\%20negro\%20eleicoes.pdf> Acesso em: 13/11/ 2016.

16. Nogueira, O. "Preconceito de marca e preconceito de origem". In: Tempo Social, revista de sociologia da USP, v. 19, n. 1, 2007.

17. Cabe relembrar que a renovação do Senado é parcial: alterna-se entre $1 / 3$ da casa (com a eleição de um/a senador/a por unidade federativa) e 2/3 (quando se elegem dois/duas representantes). Desta forma, cada UF possui sempre três representantes na Câmara Alta. Como o número de vagas é diferente em cada eleição dada a renovação parcial da Casa, o número total de membros eleitos ao Congresso também varia.

18. CFEMEA. Como parlamentares pensam os direitos das mulheres? Pesquisa na Legislatura 2007-2010 do Congresso Nacional.1 ed.Brasília : CFEMEA: SAAF/ Fundação Ford, 2009, p. 32-44.

19. Deputados e senadores, sendo a maior parte composta de deputados federais ( $86 \%$ da amostra de 321 parlamentares).

20. Paixão, M.; Carvano, L. (orgs). Relatório Anual das Desigualdades Raciais 2007-2008. Rio de Janeiro: Garamond, 2008.

21. Phillips, A. The politics of presence. Oxford University Press, 1995.

\section{DEMOGRAGIA E DIREITO DA ANTIDISGRIMINAĞ̃O: INTERSECGIONALIDADE E DISGRIMINAGĂO MÚLTIPLA NO DIREITO BRASILEIRO}

\author{
Roger Raupp Rios \\ Rodrigo da Silva
}

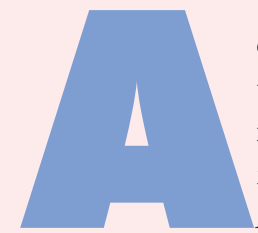

construção da democracia e a afirmação dos direitos humanos são processos concomitantes e desafiadores, em especial em contextos e experiências nacionais marcadas por autoritarismo e exclusão. Ao lado das lutas políticas e iniciativas sociais, fazem-se necessárias a formulação e a fidelidade a ordenamentos jurídicos permeados de conteúdo substantivo democrático, onde se destacam os princípios da liberdade, da igualdade e do respeito à dignidade humana.

Nesse campo, destaca-se o direito de igualdade, cuja compreensão não pode se limitar às tradicionais dimensôes formal (todos são iguais perante a lei) e material (tratar igualmente os iguais e desigualmente os desiguais, na medida de sua desigualdade). É preciso ter claro que o conteúdo jurídico e político da igualdade requer superar situações de subordinação, enfrentando "cidadanias de segunda classe". Trata-se de necessidade ainda mais pungente em sociedades como a brasileira, em que a empresa colonial valeu-se da subjugação dos povos indígenas, da escravidão imposta a africanos e da dominação de gênero como pilares de seu funcionamento.

Nesse contexto, o desenvolvimento de respostas jurídicas antidiscriminatórias vê-se profundamente desafiado, reclamando não somente clareza quanto à reprovação da discriminação em si mesma, mas também quanto à enumeração dos critérios proibidos de discriminação (primeira parte). Mais que isso, é imprescindível enfrentar a discriminação interseccional (segunda parte) e explicitar seu tratamento no direito brasileiro (terceira parte).

CONCEITO JURÍDICO DE DISCRIMINAÇÃO E CRITÉRIOS PROIBIDOS DE DISCRIMINAÇÃO O ponto de partida para o exame da discriminação interseccional é o conceito jurídico de discriminação. Adotando-se a definição desenvolvida pelos instrumentos internacionais de proteção dos direitos humanos, em especial pela Convenção Internacional sobre a Eliminação de todas as Formas de Discriminação Racial (1), pela Convenção sobre a Eliminação de Todas as Formas de Discriminação Contra a Mulher (2) e pela Convenção sobre os Direitos das Pessoas com Deficiência (3) (todos incorporados ao ordenamento jurídico brasileiro), tem-se por discriminação "qualquer distinção, exclusão, restrição ou preferência que tenha o propósito ou o feito de anular ou prejudicar o reconhecimento, gozo ou exercício em pé de igualdade de 